\title{
Optimized Flame Detection
}

\author{
Abhilash Nunes \\ Student, Xavier \\ Institute of \\ Engineering, \\ Mumbai, India.
}

\author{
Leroy Dias \\ Student, Xavier \\ Institute of \\ Engineering, \\ Mumbai, India.
}

\author{
Meena Ugale \\ Asst. Professor, \\ Xavier Institute of \\ Engineering, \\ Mumbai, India.
}

\author{
Shalem Pereira \\ Student, Xavier \\ Institute of \\ Engineering, \\ Mumbai, India.
}

\begin{abstract}
In this paper, the system focuses on optimizing the flame detection by identifying gray cycle pixels nearby the flame, which is generated because of smoke and of spreading of fire pixel and the area spread of flame. The model uses fuzzy logic or fuzzy inference system (FIS) to detect fire pixels. These techniques can be used to reduce false alarm by giving the accurate result of fire occurrence along with fire detection methods. The system also give the opportunity to adjust the system by applying different combination of fire detecting techniques which will help in implementation of system according to different sensitive area requirement.
\end{abstract}

\section{Keywords}

Fire detection, Fuzzy Inference System(FIS), Mamdani model, RGB, YCbCr.

\section{INTRODUCTION}

Fire detection system sensors are used to detect occurrence of fire and to make decision based on it. However, most of the available sensors used such as smoke detector, flame detector, heat detector etc., take time to respond. It has to be carefully placed in various locations. Also, these sensors are not suitable for open spaces because it has high false alarm rate and it cannot properly discriminates between fire and fire like colored-objects. Due to rapid developments in digital camera technology and video processing techniques, conventional fire detection methods are going to be replaced by computer vision based systems. The existing fire detection is not very much accurate.

Fire, if not detected early can cause huge amount of loss, in terms of life and property. With the increase in fire intensity, smoke and flame will be visible. So in order to detect the occurrence of fire, both fire and smoke need to be analyzed. Computer Vision based systems generally make use of three characteristic features of fire: color, motion and geometry. There are lots of fire detection systems in which the color information is used as a pre-processing step.

$\mathrm{YCbCr}$ color space is used rather than other color spaces because of its ability to distinguish luminance from chrominance information. In this paper, we have further improved the model to detect fire pixels using fuzzy logic. The implicit fuzziness or uncertainties in the rules obtained from repeated experiments and the impreciseness of the output decision is encoded in a fuzzy representation that is expressed in linguistic terms. The single output decision quantity is used to give a better likelihood that a pixel is a fire pixel. The fuzzy model achieves better discrimination between fire and fire like colored objects. Since the color based pre-processing is essential part for all image processing based fire detection systems, an efficient color model is needed.

\section{LITERATURE REVIEW}

Existing hardware sensor based smoke and heat detection systems have a high false alarm rate. Current image processing based systems also have considerably high false alarm rates and also lack accuracy [1], [3]. A fire in an image can be described by using its color properties. This color pixel can be extracted into the individual elements as $R, G$ and $B$, which can be used for color detection. Using $R$ and $G$ elements, a correlation between $G / R$ ratio and temperature distribution can be found, where, as temperature increases, the $\mathrm{G} / \mathrm{R}$ ration also increases. So, due to this, color of flame can provide useful information to guess on the temperature of a fire and also fire phase [2]. The algorithm uses both RGB and $\mathrm{YCbCr}$ color space for the detection of fire pixel intensity. The advantage of using $\mathrm{YCbCr}$ color space is that it can separate the luminance from the chrominance more effectively than RGB color space [3].This method has both higher detection rate and lower false alarm rate. In terms of RGB values, color intensity detection depends on the following inter-relation between $\mathrm{R}, \mathrm{G}$ and $\mathrm{B}$ color channels: $\mathrm{R}>\mathrm{G}$ and $\mathrm{G}>\mathrm{B}$. The combined condition for the fire region in the captured image is $\mathrm{R}>\mathrm{G}>\mathrm{B}$. But using RGB channel increases the margin for error as this color model considers and pixel having high R-channel value as a fire pixel. . The color red shows dominance in a fire image and so it should be more stressed than the other components, because R becomes the significant color channel in an RGB image of flames. This imposes another condition for $\mathrm{R}$ as to be over some predetermined threshold, RT [2]. So, input image is converted to the $\mathrm{YCbCr}$ model before detection is carried out. The input image is pre-processed for extraction of its RGB channels. These separated components are then converted to $\mathrm{Y}, \mathrm{Cb}$ and $\mathrm{Cr}$ channel image fragments Also, lighting conditions in the background may adversely affect the saturation values of flames resulting in similar $\mathrm{R}, \mathrm{G}$ and $\mathrm{B}$ values which may cause non flame pixels to be considered as flame colored. Area dispersion detection is an important concept for fire detection. It refers to detecting the spreading of the high intensity color region in the input video. When an object catches fire, the flame spreads on the object's surface over time. This detection of area dispersion is done by sequential comparison of video frames. The fire detection algorithm then processes these individual components by comparing them with each other before applying fuzzy logic to check for presence of fire in the input image. Using fuzzy interference system, the margin of error can be reduced as it allows for better distinction between fire-like regions and actual fire in the given image. 


\section{METHODOLOGY}

\subsection{Color Model for Fire}

The color model approach has been followed due to its simplicity and effectiveness. For that, color space RGB and $\mathrm{YCbCr}$ is chosen. A digital colored image has three planes: Red, Green and Blue (R, G, and B). The combination of RGB color planes gives ability to devices to represent a color in digital environment. Each color plane is quantized into discrete levels. Generally 256 (8 bits per color plane) quantization levels are used for each plane, for instance white is represented by $(\mathrm{R}, \mathrm{G}, \mathrm{B})=(255,255,255)$ and black is represented by $(R, G, B)=(0,0,0)$. A color image consists of pixels, where each pixel is represented by spatial location in rectangular grid $(x, y)$, and a color vector $(R(x, y), G(x, y)$, $\mathrm{B}(\mathrm{x}, \mathrm{y})$ ) corresponding to spatial location $(\mathrm{x}, \mathrm{y})$. [3]

In order to create model for fire, we have analyzed the images which consist of fire samples. $\mathrm{YCbCr}$ color space is chosen intentionally because of its ability to separate illumination information from chrominance more effectively than the other color spaces. The rules defined for RGB color space in order to detect possible fire-pixel candidates can be transformed into $\mathrm{YCbCr}$ color space and analysis can be performed. However the rules fall short in coming up with a single quantitative measure which can indicate how likely a given pixel is a fire pixel. The implicit fuzziness or uncertainties in the rules obtained from repeated experiments and the impreciseness of the decision variable can be encoded in a fuzzy representation. This provides a way to express the output decision in linguistic terms. The single output decision quantity expressed as a number between zero and one will then give the likelihood that a pixel is a fire-pixel or smoke- pixel. [1]

\subsection{Fire detection}

The detection of fire is carried out using the $\mathrm{YCbCr}$ samples. We have observed that the fire samples show some deterministic characteristics in their color channels of $\mathrm{Y}, \mathrm{Cb}$, and $\mathrm{Cr}$. In Figure 1, an image with fire and its color channels are shown. As can be observed from Figure 1, for a fire pixel it is more likely that, $\mathrm{Y}(\mathrm{x}, \mathrm{y})$ is greater than $\mathrm{Cb}(\mathrm{x}, \mathrm{y})$ where $(\mathrm{x}$, y) refers to pixel's spatial location. This is because the luminance information which is related to the intensity is naturally expected to be dominant for a fire pixel. Repeated experiments with fire images have shown that the greater the difference between $\mathrm{Y}(\mathrm{x}, \mathrm{y})$ and $\mathrm{Cb}(\mathrm{x}, \mathrm{y})$ components of a pixel, the higher the likelihood that it is a fire pixel. Figure 1 also hints that $\mathrm{Cb}(\mathrm{x}, \mathrm{y})$ should be smaller than $\operatorname{Cr}(\mathrm{x}, \mathrm{y})$. Similarly, a higher discrimination between $\mathrm{Cb}(\mathrm{x}, \mathrm{y})$ and $\mathrm{Cr}(\mathrm{x}$, y) means that corresponding pixel is more likely a fire pixel. So we can summarize overall relation between $\mathrm{Y}(\mathrm{x}, \mathrm{y}), \mathrm{Cb}(\mathrm{x}$, $\mathrm{y})$, and $\operatorname{Cr}(\mathrm{x}, \mathrm{y})$ as follows:

$$
Y(x, y) \geq C b(x, y) \geq \operatorname{Cr}(x, y) .
$$

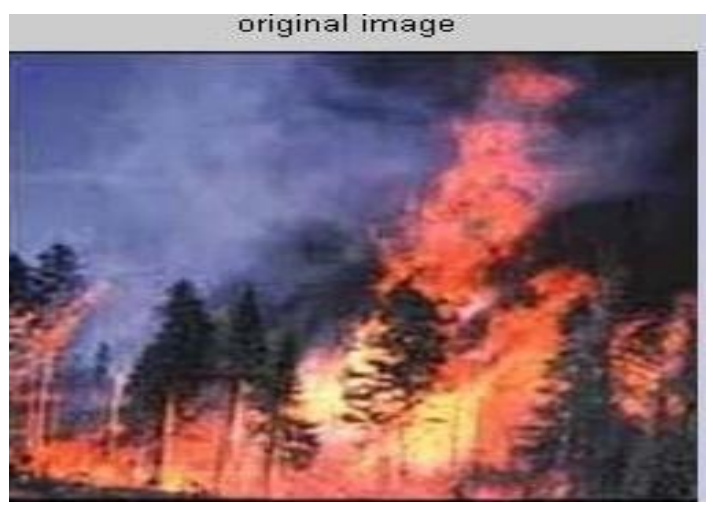

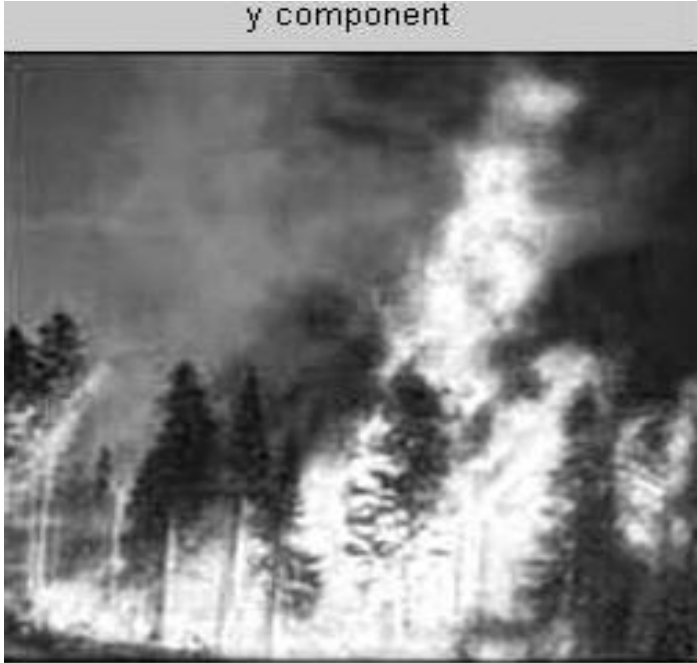
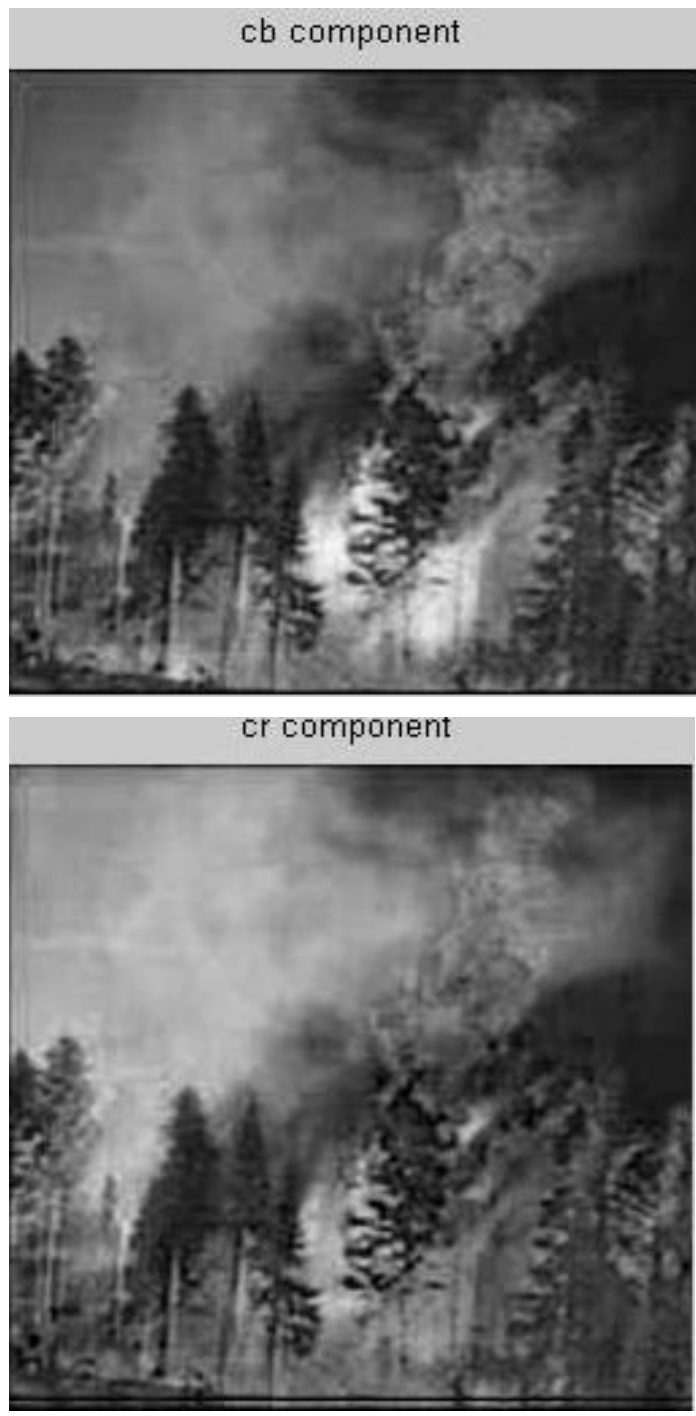

Figure 1 - RGB input image and it's $\mathrm{Y}, \mathrm{Cb}$ and $\mathrm{Cr}$ channels, Original RGB image, $\mathrm{Y}$ channel, $\mathrm{Cb}$ channel, $\mathrm{Cr}$ channel.

Let $\mathrm{P}_{\mathrm{f}}(\mathrm{x}, \mathrm{y})$ be defined as a measure that shows how likely a pixel located at spatial location $(\mathrm{x}, \mathrm{y})$ belongs to fire pixel. Its range is in the range of $[0,1]$, and it is a mapping of the observation defined in equation (1) to a quantity which describes the likelihood that a given pixel is a fire pixel. In 
order to evaluate, combination of triangular and trapezoidal membership functions are used both for the differences between $\operatorname{Cr}(\mathrm{x}, \mathrm{y})$ and $\mathrm{Cb}(\mathrm{x}, \mathrm{y})$, (i.e., $\operatorname{Cr}(\mathrm{x}, \mathrm{y})-\mathrm{Cb}(\mathrm{x}, \mathrm{y}))$, and the difference between $\mathrm{Y}(\mathrm{x}, \mathrm{y})$ and $\mathrm{Cb}(\mathrm{x}, \mathrm{y})$, (i.e., $\mathrm{Y}(\mathrm{x}, \mathrm{y})$ $\mathrm{Cb}(\mathrm{x}, \mathrm{y}))$. [1]

Fig. $2 \mathrm{a}, 2 \mathrm{~b}$ and $2 \mathrm{c}$ show respectively membership functions for $\mathrm{Y}(\mathrm{x}, \mathrm{y})-\mathrm{Cb}(\mathrm{x}, \mathrm{y}), \mathrm{Cr}(\mathrm{x}, \mathrm{y})-\mathrm{Cb}(\mathrm{x}, \mathrm{y})$ and $\mathrm{P}_{\mathrm{f}}(\mathrm{x}, \mathrm{y})$. It should be noted that, Mamdani type fuzzy inference system (FIS) is used with the rules defined in Table 1 . The distribution of membership functions and rules defined in

Table 1 is found using experimental analysis. Table 1 show the rules used in our FIS. The rules are defined in such a way to reflect our expectation for a fire pixel. A total of 16 rules are constructed to account for all possible combinations of input variables.[1]

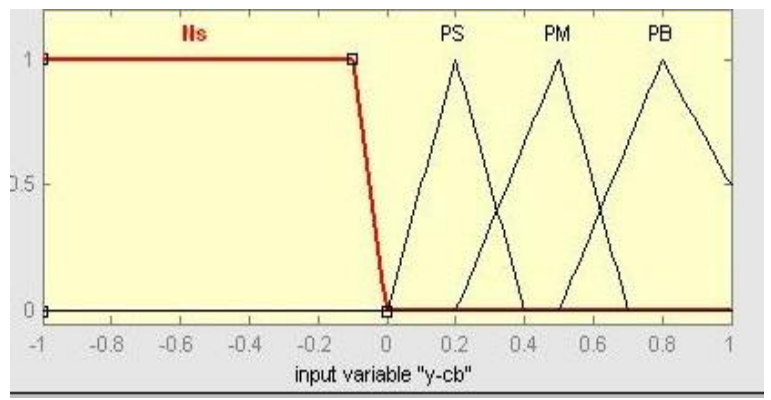

(a)

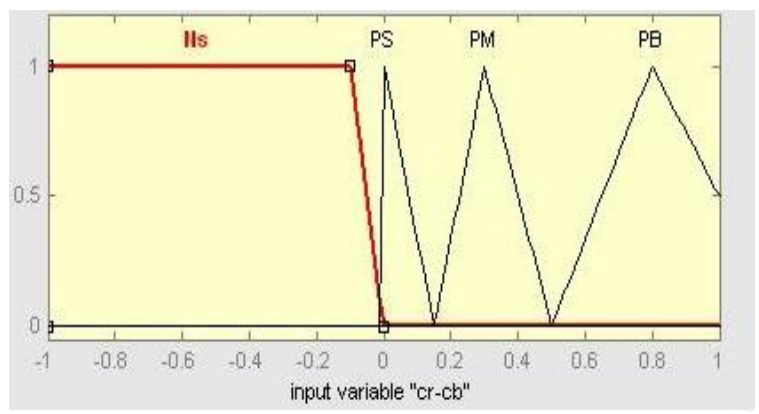

(b)

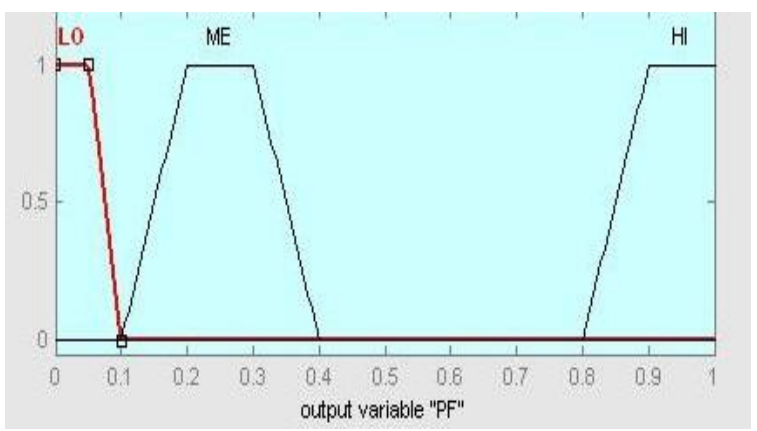

(c)

Figure 2 - Membership functions for (a) $Y(x, y)-C b(x, y)$, (b) $\mathrm{Cr}(\mathrm{x}, \mathrm{y})-\mathrm{Cb}(\mathrm{x}, \mathrm{y})$, and (c) $\mathbf{P}_{\mathrm{f}}(\mathrm{x}, \mathrm{y})$.

In the shown original image, each channel is normalized with respect to following formula:

$$
\begin{aligned}
Y & =Y \div \operatorname{Imax} ; \quad C b=C b \div \operatorname{Imax} ; \\
C r & =C r \div \operatorname{Imax} \ldots \ldots \ldots \ldots \ldots \ldots \ldots \ldots \ldots \ldots \ldots \ldots \ldots \ldots
\end{aligned}
$$

Where Imax is the maximum intensity value in set defined by the combination of $\mathrm{Y}, \mathrm{Cb}$, and $\mathrm{Cr}$ channels. The equation in (2) normalizes all the samples to the interval of [0 1]. So that their difference are in the range of [-1 1] which is used in membership function definitions as shown in Figure 2. Given a set of inputs from $\mathrm{Y}(\mathrm{x}, \mathrm{y})-\mathrm{Cb}(\mathrm{x}, \mathrm{y})$ and $\mathrm{Cr}(\mathrm{x}, \mathrm{y})-\mathrm{Cb}(\mathrm{x}, \mathrm{y})$, the crisp output of the fuzzy system is computed as follows: first, the inputs are fuzzified based on the membership functions shown in Figure $2 a$ and Figure $2 b$. Then, the min implication operator is applied on the fuzzy rules. Centre of area defuzzification is applied on the union of all rule outputs in order to find a quantitative measure for $\mathrm{P}_{\mathrm{f}}(\mathrm{x}, \mathrm{y}) . \mathrm{Y}(\mathrm{x}, \mathrm{y})$ $\mathrm{Cb}(\mathrm{x}, \mathrm{y})$, and $\mathrm{Cr}(\mathrm{x}, \mathrm{y})-\mathrm{Cb}(\mathrm{x}, \mathrm{y})$ is normalized to $[-1,1]$ before entering into FIS. The surface for 16 rules is shown in Figure 3. The figure shows the likelihood $\mathrm{P}_{\mathrm{f}}(\mathrm{x}, \mathrm{y})$, as a function of inputs $\mathrm{Y}(\mathrm{x}, \mathrm{y})-\mathrm{Cb}(\mathrm{x}, \mathrm{y})$ and $\mathrm{Cr}(\mathrm{x}, \mathrm{y})-\mathrm{Cb}(\mathrm{x}, \mathrm{y})$. The visual appearance of Figure 3 is as expected and interpreted as follows; when $\mathrm{Y}(\mathrm{x}, \mathrm{y})-\mathrm{Cb}(\mathrm{x}, \mathrm{y})$ is less than zero, corresponding $\mathrm{P}_{\mathrm{f}}(\mathrm{x}, \mathrm{y})$ approaches to 0 , and if both $\mathrm{Y}(\mathrm{x}, \mathrm{y})-\mathrm{Cb}(\mathrm{x}, \mathrm{y})$ and $\mathrm{Cr}(\mathrm{x}, \mathrm{y})-\mathrm{Cb}(\mathrm{x}, \mathrm{y})$ gets closer to value of 1.0 , the approaches to 1. The plateau below the peak is used to give low likelihood to objects which show similar behavior to fire color but it is not the fire, i.e. the smoke pixels around fire regions which is colored like fire because of reflectance property of smoke pixels. It is clear from the surface that, the $\mathrm{P}_{\mathrm{f}}$ gets high values at the values where $\mathrm{Y}(\mathrm{x}, \mathrm{y})-\mathrm{Cb}(\mathrm{x}, \mathrm{y})$ and $\operatorname{Cr}(\mathrm{x}, \mathrm{y})-\mathrm{Cb}(\mathrm{x}, \mathrm{y})$ behaves like fire. [1]

\begin{tabular}{|c|c|c|c|c|c|}
\hline \multirow{2}{*}{\multicolumn{2}{|c|}{$P_{f}(x, y)$}} & \multicolumn{4}{|c|}{$\mathrm{Cr}(\mathrm{x}, \mathrm{y})-\mathrm{Cb}(\mathrm{x}, \mathrm{y})$} \\
\hline & & NS & PS & PM & PB \\
\hline \multirow{4}{*}{ 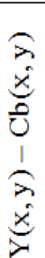 } & NS & LO & LO & LO & LO \\
\hline & PS & LO & LO & $\mathrm{HI}$ & $\mathrm{HI}$ \\
\hline & PM & LO & $\mathrm{HI}$ & $\mathrm{HI}$ & ME \\
\hline & PB & LO & $\mathrm{ME}$ & $\mathrm{ME}$ & $\mathrm{ME}$ \\
\hline
\end{tabular}

Table 1 - Rule table for fuzzy inference system

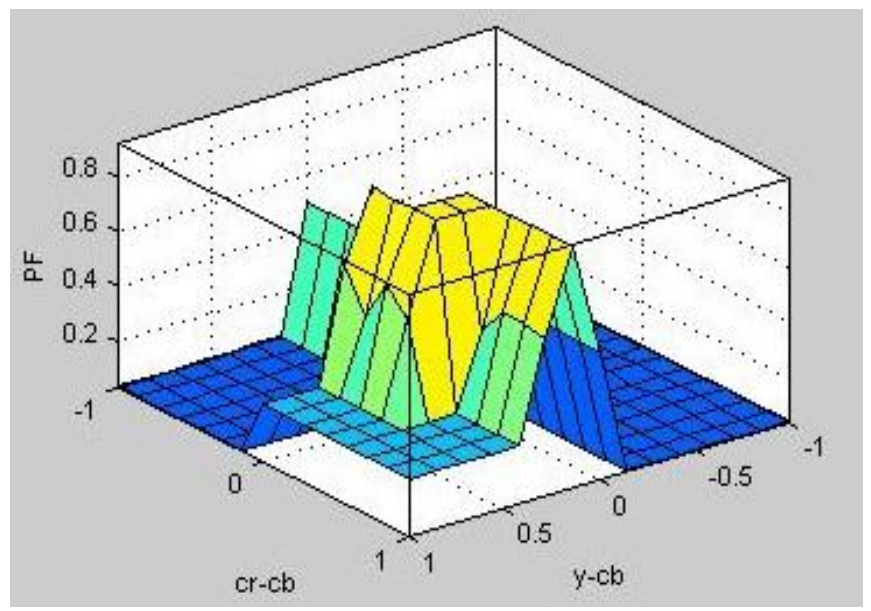

Figure 3- View of surface of rules given in Table 1 and used in FIS.

Figure 4 shows some images and its corresponding. It is clear that $P_{f}$ gets higher values over fire regions and lower values over non-fire regions. Note that, $\mathrm{P}_{\mathrm{f}}$ has values in the range of [ [ $\left.\begin{array}{ll}0 & 1\end{array}\right]$. 

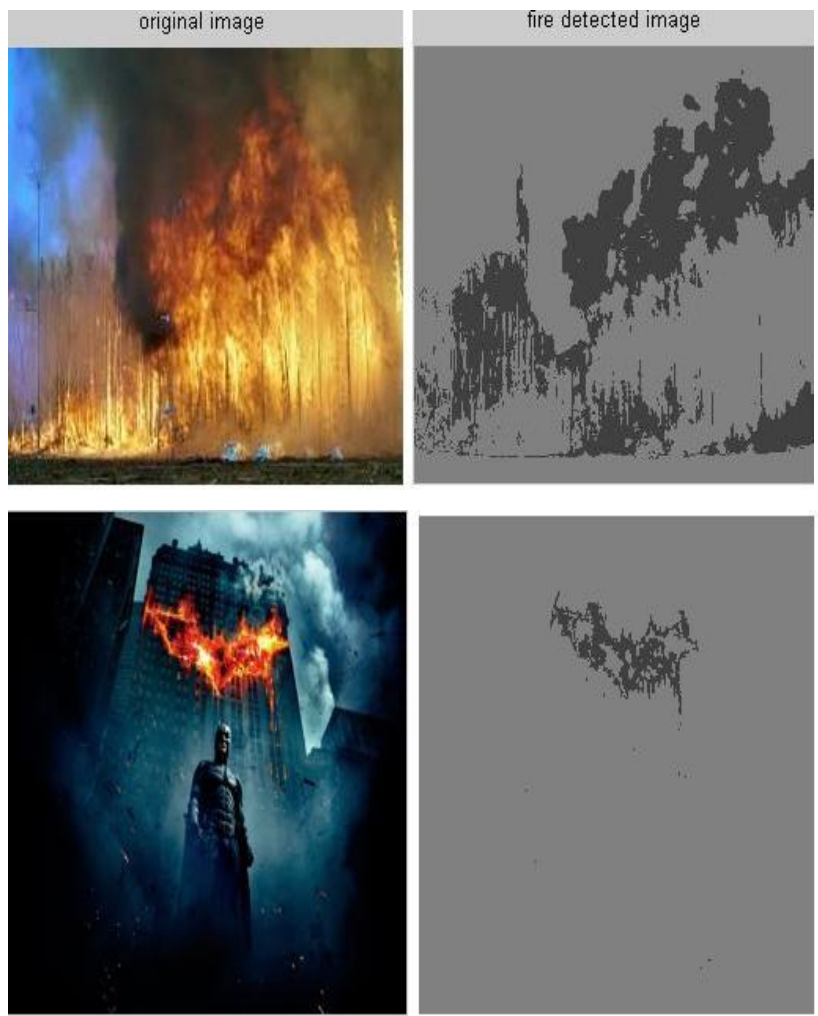

(a)

(b)

Figure 4 - RGB input image and it's Pf, Column (a) RGB input image, Column (b) $P_{f}$ for corresponding input image.

\section{RESULTS AND CONCLUSION}

\subsection{Results}

In table-2, for comparison purpose two sets of images are collected which consist of total 50 images. From these two sets of images, one set of 25 images is composed of images which consist of fire and gives successful detection for 24 images with the accuracy of $96 \%$, whereas in the another set of 25 images contain images that does not consist of fire, but fire like colored images which gives successful detection for 15 fire like colored images with the accuracy of $60 \%$. Two type of comparison is carried out; one for evaluation of the correct fire detection rate and the other is for the false alarm rate. Now, in table-3, out of 25 fired images, false alarm is detected just for one image and gives accuracy of $4 \%$, while for non-fire images, out of 25 , false alarm is detected for 40 images with the accuracy of $40 \%$.

Table 2- Results of Fire Detection

\begin{tabular}{|c|c|c|c|}
\hline Image Type & $\begin{array}{c}\text { Number } \\
\text { of Images }\end{array}$ & $\begin{array}{c}\text { Successful } \\
\text { Detection }\end{array}$ & $\begin{array}{c}\text { Accuracy } \\
(\%)\end{array}$ \\
\hline Fire Image & 25 & 24 & 96 \\
\hline $\begin{array}{c}\text { Non-fire } \\
\text { Image }\end{array}$ & 25 & 15 & 60 \\
\hline
\end{tabular}

Table3- Results of False Alarm Rate

\begin{tabular}{|c|c|c|c|}
\hline Image Type & $\begin{array}{c}\text { Number of } \\
\text { Images }\end{array}$ & $\begin{array}{c}\text { False } \\
\text { Alarm }\end{array}$ & $\begin{array}{c}\text { Accuracy } \\
(\%)\end{array}$ \\
\hline Fire Image & 25 & 1 & 04 \\
\hline $\begin{array}{c}\text { Non-fire } \\
\text { Image }\end{array}$ & 25 & 10 & 40 \\
\hline
\end{tabular}

\subsection{Conclusion}

We have implemented fire detection, using the concept of fuzzy logic, which replace the existing heuristic rules and make the classification more robust in effectively discriminating fire and fire like colored object. The model achieves up to $96 \%$ correct fire detection rate with a $40 \%$ false alarm rate.

\section{REFERENCES}

[1] TurgayÇelik, HüseyinÖzkaramanlı and HasanDemirel, "Fire and Smoke Detection without Sensors: Image Processing Based Approach", 15th European Signal Processing Conference (EUSIPCO 2007), Poznan, Poland, September-3-7, 2007.

[2] GauravYadav,Vikas Gupta, Vinod Gaur and Dr. MahuaBhattacharya, "Optimized Flame Detection Using Image Processing Based Techniques", ISSN: 0976-5166, Vol. 3 No. 2, April-May, 2012.

[3] VipinVenu, "Image Processing Based Forest Fire Detection", ISSN 2250-2459, Volume 2, Issue 2, February 2012.

[4] Chen, T., Wu, P., Chiou, Y., "An early fire-detection method based on image processing", Proc. IEEE Internat. Conf. on Image Processing, ICIP'04, pp. 1707-1710, 2004.

[5] Klir, G. J., Yuan B., "Fuzzy Sets and Fuzzy Logic", Prentice Hall, 1995.

[6] Mathews, J.H., Fink, K.D., "Numerical Methods using matlab", Prentice Hall, 1999.

[7] Turgay Celik, Huseyin Ozkaramanli, Hasan Demirel, "Fire Pixel Classification Using Fuzzy Logic and Statistical Color Model”, ICASSP 2007.

[8] T. Chen, P. Wu, and Y. Chiou (2004): "An early firedetection method based on image processing", in ICIP '04, pp.1707-1710.

[9] C.-B. Liu, N. Ahuja (2004): "Vision based fire detection", Proceedings of the 17th International Conference on Pattern Recognition (ICPR' 04), Vol.4, pp. 134-137.

[10] S. Noda, K. Ueda (1994): "Fire detection in tunnels using an image processing method", in Vehicle Navigation \& Information Systems Conference Proceedings, pp. 57-62.

[11] TurgayCelik (2010): "Fast and Efficient Method for Fire Detection Using Image Processing", ETRI Journal, Volume 32, Number 6. 